\title{
Aerosol fluxes and dynamics within and above a tropical rainforest in South-East Asia
}

\author{
J. D. Whitehead ${ }^{1}$, M. W. Gallagher ${ }^{1}$, J. R. Dorsey ${ }^{1}$, N. Robinson ${ }^{1}$, A. M. Gabey ${ }^{1}$, H. Coe ${ }^{1}$, G. McFiggans ${ }^{1}$, \\ M. J. Flynn ${ }^{1}$, J. Ryder ${ }^{1,2}$, E. Nemitz ${ }^{2}$, and F. Davies ${ }^{3, *}$ \\ ${ }^{1}$ Centre for Atmospheric Science, SEAES, University of Manchester, Simon Building, Brunswick Street, \\ Manchester M13 9PL, UK \\ ${ }^{2}$ Centre for Ecology and Hydrology, Edinburgh Research Station, Bush Estate, Penicuik, Midlothian, EH26 0QB, UK \\ ${ }^{3}$ School of Environment and Life Sciences, Peel Building, University of Salford, Salford, M5 4WT, UK \\ *now at: School of Earth and Environment, University of Leeds, Leeds, LS2 9JT, UK
}

Received: 26 April 2010 - Published in Atmos. Chem. Phys. Discuss.: 7 May 2010

Revised: 9 August 2010 - Accepted: 28 September 2010 - Published: 5 October 2010

\begin{abstract}
Atmospheric aerosol measurements were conducted near Danum Valley, in the Malaysian state of Sabah, North-East Borneo, as part of the OP3 and ACES projects, in April and June/July 2008. Here, aerosol fluxes and diurnal variability in and above the rainforest canopy were examined in order to gain an understanding of their behaviour in the surface layer of the South-East Asian rainforest. Aerosol fluxes were calculated by eddy covariance from measurements above the rainforest canopy on the Global Atmosphere Watch (GAW) tower. Upward fluxes were seen on most mornings between 09:00 and 11:00 local time and this could be attributed to venting of the nocturnal boundary layer as it broke up in the morning. Measurements were also conducted within the canopy and trunk space at a nearby site. Profiles in aerosol number concentrations were investigated using GRIMM Optical Particle Counters (OPCs) at various levels within the rainforest canopy and trunk space, as well as a single OPC on a vertically moving platform. These showed an overnight increase in larger particles $(1-20 \mu \mathrm{m})$ at all levels, but much more prominently near the top of the canopy, which could be attributed to fog formation. At ground level, number concentrations in this size range correlated with enhancements in biological aerosol concentrations, measured using a Wide Issue Bioaerosol Spectrometer (WIBS) located near the forest floor, suggesting that coarse particle number concentrations were dominated by biological aerosols. A comparison of particle number concentra-
\end{abstract}

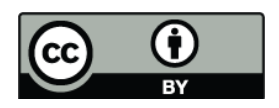

Correspondence to: J. D. Whitehead (james.whitehead@manchester.ac.uk) tions (in the size range $0.5-1.0 \mu \mathrm{m}$ ) between above canopy and the trunk space showed correlations, despite turbulence data suggesting persistent decoupling between the two measurement sites. These correlations often relied on a shift of the particle time-series against each other, implying a time delay in observations between the sites, which varied according to time of day. This lag time was shortest during the middle of the day by a significant margin. This was not observed for aerosols larger than $1.0 \mu \mathrm{m}$. Further evidence of daytime coupling between above canopy and the trunk space in terms of aerosol measurements is implied by comparison of measurements from an Aerosol Mass Spectrometer (AMS) at the GAW tower and simultaneous bag sampling at the in-canopy site, subsequently analysed with the AMS. Transport of particles through the canopy seems to occur through large-scale, sporadic turbulent events, suggesting that the coupling between the canopy space and the air above is due to these ventilation events.

\section{Introduction}

Atmospheric aerosol particles are important due to their impact on climate, visibility and human health. Aerosols influence the Earth's radiative balance either directly, by scattering incoming solar radiation, or indirectly, by modifying the radiative properties of clouds, and their lifetime (IPCC, 2007). It is therefore important to understand the processes by which aerosols are produced or lost from the atmosphere.

Forests can act as both sources and sinks of atmospheric aerosol particles. Aerosol formation and growth has been

Published by Copernicus Publications on behalf of the European Geosciences Union. 
observed in forests at a number of locations (e.g. Kavouras et al., 1998; Kulmala et al., 1998), likely resulting from the oxidation of volatile organic compounds (VOCs). On the other hand, aerosol deposition to forest canopies has been extensively observed and quantified (see Pryor et al., 2008, for a review), and represents an important aerosol removal mechanism from the atmosphere. Forest-atmosphere exchange is further complicated by the various layers of the forest, particularly in tropical rainforests, where a dense upper canopy often results in a decoupling between the space beneath it and the atmosphere above canopy (e.g. Kruijt et al., 2000). Exchange between these layers usually relies on large-scale turbulence events (e.g. Fitzjarrald et al., 1990). Understanding these mechanisms is important in explaining not only how atmospheric constituents may penetrate down through the canopy, but also how particles formed or emitted in the trunk space below the canopy might escape. This is also of particular interest in describing how biological particles such as fungal spores can distribute over a wider area.

Many studies have been conducted in temperate and boreal forests at various locations, while most of the measurements in tropical forests (which make up over half the world's forests) have largely focussed on the Amazon (e.g. Artaxo et al., 1990, 1994, 2002; Andreae et al., 2002; Zhou et al., 2002; Guyon et al., 2003; Rissler et al., 2006; Farmer et al., 2008; Ahlm et al., 2009). The work from the Amazon has found a sharp contrast in aerosol composition and concentration between wet and dry seasons with biomass burning emissions dominating in the dry season (Artaxo et al., 1994, 2002). The rainforest is also a significant source of biogenic aerosols, which are detected all year round and dominate in the wet season (Artaxo et al., 2002). This biogenic aerosol is likely made up of primary biological particles (e.g. pollen, spores, bacteria, plant fragments) and secondary aerosols from the oxidation of gases emitted by the forest (Andreae et al., 2002), however Zhou et al. (2002) and Rissler et al. (2006) found no evidence of new particle production in the rainforest. Locally produced biological particles have also been found to contribute to ice nucleation in the Amazon basin (Prenni et al., 2009).

Aerosol deposition may be a significant source of nutrients to the rainforest ecosystem, or part of the internal recycling (Artaxo et al., 2002). Deposition may occur as dry or wet (including fog, which is known to form frequently in tropical rainforests). Dry deposition can be quantified by flux measurements, however there have been very few direct measurements of aerosol fluxes above a tropical rainforest (Ahlm et al., 2009). Such measurements are necessary to help quantify the exchange of aerosols between the forest and the atmosphere.

To the authors' knowledge, there have been no published measurements of aerosol fluxes and dynamics in the Maritime Continent region of South-East Asia (so named for its unique mixture of land masses and seas distributed over a very large area). In this region, the patchwork layout of islands and seas is likely to result in different atmospheric chemistry, and more of a marine influence over the rainforests compared to the continental landmass of the Amazon rainforest. Both regions, however, are undergoing rapid land-use changes, potentially resulting in significant changes to regional atmospheric composition and climate (Andreae et al., 2002). This paper presents the first measurements of aerosol fluxes and vertical transport in a South-East Asian rainforest. The study sought to examine the behaviour of aerosols throughout and above the rainforest canopy in order to determine: (1) the processes by which particles may be transported through the rainforest canopy; (2) how representative in-canopy aerosols are of those above the canopy; and (3) the behaviour of aerosols above the canopy.

Following a description of the methodology (Sect. 2), the Results and Discussion section first considers the difference between the micrometeorology above canopy and that of the trunk space (i.e. below canopy) (Sect. 3.1). Sections 3.2 and 3.3 study the measurements above the canopy, including the fluxes, while Sect. 3.4 looks at the measurements in the canopy and the trunk space. Section 3.5 examines the coupling across the rainforest canopy in terms of sizesegregated aerosol number concentrations, and the results are summarised together in the final section to describe a picture of the behaviour of aerosols in the surface layer of a SouthEast Asian rainforest.

While this work discusses the fluxes, dynamics and variability of aerosols in the rainforest, aerosol chemistry will be considered in separate papers (e.g. Phillips et al., 2010). These measurements were conducted as part of the NERC funded OP3 (Oxidant and Particle Photochemical Processes) and ACES (Aerosol Coupling in the Earth System) projects.

\section{Measurements}

\subsection{Measurement sites}

Measurements took place in tropical rainforest near the Danum Valley Conservation Area in the Sabah Federal State of Malaysia in North-East Borneo. The forest in and around Danum Valley is categorised as a tropical lowland evergreen rainforest with a height varying between $25-45 \mathrm{~m}$ and an estimated average height of $35 \mathrm{~m}$ within the footprint of the measurements. Tree species in this region consist mainly of primary lowland dipterocarp (Newbery et al., 1999). The area around the measurement locations was selectively logged in 1988 and has since been managed by the Innoprise-FACE Foundation Rainforest Rehabilitation Project (INFAPRO), which has replanted with dipterocarp species. Nevertheless, the forest is patchy with areas dominated by secondary pioneer species. The topography is hilly, with steep sided valleys approximately $200 \mathrm{~m}$ deep. Figure 1 displays the elevation variation of the area and the location of the measurement sites. The area receives an annual mean rainfall of 


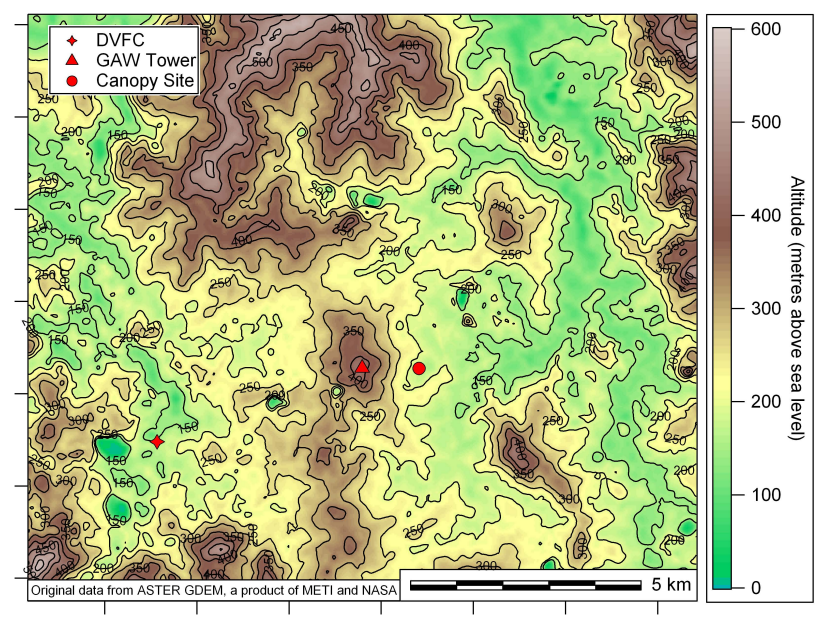

Fig. 1. Relief map of the area showing site locations. Original data of ASTER GDEM is the property of METI and NASA.

2778 mm (L. S. Fook, Malaysia Meteorological Dept., personal communication, 2008) with January and October being the wettest months receiving 311 and $290 \mathrm{~mm}$ respectively. April is typically the driest month $(159 \mathrm{~mm})$.

Measurements were made at two locations. The abovecanopy measurements were made on the $100 \mathrm{~m}$ tall Global Atmosphere Watch (GAW) tower, situated in a wide clearing at the top of the Bukit Atur ridge ( $4^{\circ} 58^{\prime} 49^{\prime \prime} \mathrm{N} 117^{\circ} 50^{\prime} 39^{\prime \prime} \mathrm{E}$, elevation $426 \mathrm{~m}$ ). The trunk space and canopy measurements were made $1.2 \mathrm{~km}$ to the east $\left(4^{\circ} 58^{\prime} 49^{\prime \prime} \mathrm{N} 117^{\circ} 51^{\prime} 19^{\prime \prime} \mathrm{E}\right.$, elevation $200 \mathrm{~m}$ ) of Bukit Atur, near the INFRAPRO nursery. At these locations, sunrise and sunset occurred around 06:00 and 18:20 respectively $( \pm 6 \mathrm{~min}$ over the period of measurements) local time (=GMT +8$)$. The measurements were made over two separate periods in 2008: the first in April, and the second in June and July. More detail regarding the measurement sites may be found in Hewitt et al. (2010).

\subsection{Above canopy micrometeorology}

Flux measurements were made at a height of $47 \mathrm{~m}$ on the GAW tower. The sides of the Bukit Atur ridge are steep and the tree height at the top is smaller than further down, so measurements on the GAW tower are representative of above canopy air within a footprint that covers a large area of forest. Instruments consisted of an ultrasonic anemometer (RM Young, model 81000), a temperature and humidity probe (Vaisala, model HMP-100), a Krypton hygrometer (KH2O; Campbell Scientific Ltd.), two fast-response ozone sensors (a GFAS, model OS-G-2 and a Rapid Ozone Flux Instrument, ROFI, CEH), and two ultrafine Condensation Particle Counters (CPCs; TSI, models 3010 and 3025A). The CPCs were calibrated and serviced prior to deployment in Borneo. These models have stated lower size cut-offs of $10 \mathrm{~nm}$ (3010) and $3 \mathrm{~nm}$ (3025A) (see, e.g. Mertes et al., 1995; Quant et al.,
1992). While the absolute lower size cut-offs of the instruments used here have not been verified, they have previously been used side-by-side to measure nucleation mode aerosols through the difference in lower size cut-off, both in an urban environment in conjunction with a DMPS (unpublished data) and at a coastal location (Whitehead et al., 2010). Both instruments had a common inlet, the mouth of which was positioned close to the anemometer array and sampled via a $1 / 4$ inch diameter stainless steel tube with a length of $1.8 \mathrm{~m}$.

Particle and ozone fluxes were calculated using the eddycovariance (EC) technique. This is the simplest, most direct method for measuring vertical exchange fluxes of atmospheric trace gases. It is based on the Reynolds decomposition of a turbulent quantity such as concentration $(\chi)$ into its time-averaged component $(\bar{\chi})$, and its instantaneous perturbation $\left(\chi^{\prime}\right)$ :

$\chi=\bar{\chi}+\chi^{\prime}$

The vertical flux of $\chi$ is then defined as the covariance between $\chi$ and the vertical component of wind speed, $w$ (e.g. Foken and Wichura, 1996):

$F_{\chi}=\overline{w^{\prime} \chi^{\prime}}=\overline{w \chi}-\bar{w} \bar{\chi}$

Sonic anemometer data were sampled at $20 \mathrm{~Hz}$. The ozone fluxes will be reported in an associated paper, (Muller et al., 2010). The high frequency data were first subjected to a spike removal algorithm, using the method described by Vickers and Mahrt (1997). Online fluxes of particles were calculated for $30 \mathrm{~min}$ averaging periods. A study conducted at $75 \mathrm{~m}$ on the GAW tower found that sensible heat fluxes averaged over two hours were $8 \%$ greater than those averaged over $30 \mathrm{~min}$ (Helfter et al., 2010; Langford et al., 2010). A similar result was seen at the $47 \mathrm{~m}$ level suggesting that larger eddies were missed by the shorter averaging period. Particle number concentrations were recorded from the CPCs once per second, similar to the internal time response of these counters (e.g. Heim et al., 2004). The attenuation of the eddy covariance fluxes due to this limited sampling frequency was checked using the method of Horst (1997):

$\frac{F_{m}}{F}=\frac{1}{1+\left(2 \pi n_{m} \tau_{c} \bar{u} / z\right)^{\alpha}}$

where $\tau_{c}$ is the characteristic time constant of the sensor response ( $1 \mathrm{~s}$ in this case), $\bar{u}$ is the mean wind speed and $z$ is the measurement height. For unstable and neutral stratification, $z / L \leq 0$,

$\alpha=7 / 8 ; n_{m}=0.085$

while for stable stratification, $z / L>0$,

$\alpha=1 ; n_{m}=2.0-\frac{1.915}{1+0.5 \frac{z}{L}}$

From this method, particle fluxes were underestimated by $6 \%$ on average over the whole campaign, due to the limited sampling frequency of the CPC. This flux loss is modest due to 
the large average eddy size associated with the high measurement height.

Particle number concentration time series data were treated automatically for lag times induced by sampling down the inlets and checked using autocorrelation calculations. Standard two-dimensional geometric coordinate rotations were performed on the anemometer data to correct for any deviations in the alignment of the sonic anemometer (see, e.g., Foken, 2006). During post-processing, the CPC data was also detrended using a running mean window filter with a width of $200 \mathrm{~s}$, in order to reduce the number of nonstationarities in the particle number concentration time series data (McMillen, 1988). Following this, fluxes were checked for stationarity using the criterion described by Foken and Wichura (1996), whereby the covariance, $\overline{w^{\prime} \chi^{\prime}}$, over the flux averaging interval was compared to the mean covariance of 5 min sub-intervals. The percentage difference indicates the degree of non-stationarity. For a difference of $30 \%, 77 \%$ of the fluxes were found to be non-stationary, while for a difference of $60 \%$, (as used by Järvi et al., 2009, for particle fluxes in an urban environment) $58 \%$ of the fluxes were nonstationary. These high rates of non-stationarities were likely due to constant rapidly changing conditions at the measurement site. These fluxes were flagged but not rejected, and the implications on the results are discussed briefly in Sect. 3.2.

It should be noted that this flux measurement, carried out well above the forest canopy, represents the local vertical flux at the measurement height and that effects due to storage, chemistry and advection are not quantified here. The measurements are interpreted accordingly. The effects of chemistry are discussed in more detail in the interpretation of the chemically resolved flux measurements by Phillips et al. (2010).

\subsection{Other above canopy measurements}

The above-canopy aerosol size distributions reported here were measured with an Aerodynamic Particle Sizer (APS; TSI, model 3321) and a Differential Mobility Particle Sizer (DMPS; Williams et al., 2000). The APS monitored particles in the aerodynamic size range $0.5-20 \mu \mathrm{m}$, with 52 logarithmic size channels, while the DMPS measured in the mobility size range $22-670 \mathrm{~nm}$ over 29 channels. For these concentration measurements, ambient air was sampled from a height of $33 \mathrm{~m}$ at $15001 \mathrm{~min}^{-1}$ (turbulent flow) down a $30 \mathrm{~m}$ inlet of diameter $150 \mathrm{~mm}$. The inlet was insulated to mitigate the effects of solar radiative heating. By sampling rapidly, the effect of the temperature differential along its length was minimised. Air was sub-sampled isokinetically at ground level at $401 \mathrm{~min}^{-1}$ (laminar flow) from the main inlet by a $16 \mathrm{~mm}$ diameter tube. It was then passed through a Nafion drier before entering the laboratory via a $44 \mathrm{~mm}$ diameter tube, from which all laboratory instruments sampled. The median relative humidity of the sampled air in the container was $76 \%$ and varied between 63 and 83\% (5th and 95th percentiles).
The transmission efficiency of the inlet was tested using two GRIMM optical particle counters (OPCs): one situated at the top, and one sampling off the inlet. The OPCs had been intercalibrated with each other as described in Sect. 2.4. This test showed that the aerosol transmission efficiency of the inlet was around $70 \%$ for the submicron range of the OPC $(0.3-$ $1.0 \mu \mathrm{m}$ ), but reduced to around $30 \%$ for supermicron particles (up to $20 \mu \mathrm{m}$ ). The transmission efficiency for smaller size range particles was tested by comparison of the total concentration from the DMPS (at the bottom of the inlet) and the CPC 3010 (at $47 \mathrm{~m}$ on the tower). This showed a strong correlation $\left(r^{2}=0.86\right)$ with a slope of 0.96 suggesting losses in the small size range were $4 \%$ or less.

A Particle Volume Monitor (PVM-100) was located at approximately $32 \mathrm{~m}$ on the GAW tower in order to measure the Liquid Water Content (LWC; Gerber, 1991). Situated near to this was a second ultrasonic anemometer (RM Young, model 81000). These latter two instruments operated during the first measurement phase only.

\subsection{In-canopy micrometeorology}

At the canopy site three-dimensional wind speed, heat flux and turbulence data were recorded at $50 \mathrm{~Hz}$ using a sonic anemometer (Gill R3-50, response time $50 \mathrm{~Hz}$ but logged at $10 \mathrm{~Hz}$, velocity range 0 to $45 \mathrm{~m} \mathrm{~s}^{-1}$, resolution $0.01 \mathrm{~m} \mathrm{~s}^{-1}$, accuracy $\pm 1.0 \% \mathrm{RMS}$, speed of sound resolution $<0.01 \mathrm{~m} \mathrm{~s}^{-1}$ and equivalent temperature resolution $< \pm 0.5 \%$ at $20^{\circ} \mathrm{C}$ ) mounted on a $2 \mathrm{~m}$ mast secured to the rainforest floor. Spikes were removed from the high frequency data using the method described by Vickers and Mahrt (1997). Fluxes and micrometeorological parameters were calculated using the same techniques as were used on the GAW tower. Temperature and relative humidity $(\mathrm{RH})$ were measured by a Vaisala HMT337 heated sensor consisting of a PT100 RTD sensor, (range -70 to $+180^{\circ} \mathrm{C}$, accuracy $\pm 0.2{ }^{\circ} \mathrm{C}$ at $20^{\circ} \mathrm{C}$ ) and a HUMICAP $\odot 180 \mathrm{R}$ sensor for humidity (range 0 to $100 \% \mathrm{RH}$, accuracy $\pm 1.0 \%$ from 0 to $90 \%$ and $\pm 1.7 \%$ from 90 to $100 \%$ ) for improved performance in a near condensing environment. This was mounted on the same mast, along with a pyrgeometer (Kipp \& Zonen, model CNR1) to measure upward and downward short and long-wave radiation at $1 \mathrm{~Hz}$.

\subsection{In-canopy aerosol number size distributions}

GRIMM Dust Monitor Optical Particle Counters (OPCs; model 1.108; size range $0.3-20 \mu \mathrm{m}$, with 15 size channels) were installed on platforms mounted on a tree (sp. Canarium decumanum burseraceae, approximately $40 \mathrm{~m}$ tall) at heights $8 \mathrm{~m}, 16 \mathrm{~m}$ and $32 \mathrm{~m}$, and on the mast at the forest floor (fixed OPCs). The four OPCs were used to provide near continuous ambient aerosol size distribution measurements throughout the project. Inter-calibration with each other at the start and end of the measurements showed one of the units (at $8 \mathrm{~m}$ ) 
Table 1. Correction factors for each OPC when calibrated against OPC 1 (situated on the mast on the forest floor). The text in brackets next to the OPC number describes its position in the canopy.

\begin{tabular}{|c|c|c|c|c|c|c|c|c|c|c|c|c|c|c|c|}
\hline \multirow[b]{2}{*}{ OPC number } & \multicolumn{15}{|c|}{ Channel (lower cut in $\mu \mathrm{m}$ ) } \\
\hline & 0.3 & 0.4 & 0.5 & 0.65 & 0.8 & 1.0 & 1.6 & 2.0 & 3.0 & 4.0 & 5.0 & 7.5 & 10 & 15 & 20 \\
\hline $2(8 \mathrm{~m})$ & 0.39 & 0.40 & 0.40 & 0.64 & 0.97 & 0.45 & 0.27 & 0.12 & 0.02 & 0.02 & 0.09 & 0.09 & 0.07 & 0.03 & 0.04 \\
\hline $3(16 \mathrm{~m} /$ winch $)$ & 0.95 & 0.85 & 0.84 & 0.96 & 0.82 & 0.51 & 0.39 & 0.52 & 0.54 & 0.61 & 0.54 & 0.37 & 0.49 & 0.37 & 0.78 \\
\hline $4(32 \mathrm{~m})$ & 0.64 & 0.82 & 0.76 & 0.82 & 0.69 & 0.67 & 0.45 & 0.75 & 0.44 & 0.58 & 0.58 & 0.46 & 0.38 & 0.13 & 0.32 \\
\hline
\end{tabular}

underperformed compared to a pre-calibrated reference analyser (forest floor). The slopes of this and the other OPCs when plotted against the reference OPC are shown in Table 1 . Therefore, the data from the $8 \mathrm{~m}$ OPC has been discarded, and only the data from the other levels, calibrated accordingly, will be presented here. Towards the end of the measurement period one of the OPCs (taken from $16 \mathrm{~m}$ ) was mounted on an automatic winch system, which continuously raised and lowered it next to the measurement tree from the 12th until the 19 July (see Ryder et al., 2010). This system had a height range between $2 \mathrm{~m}$ and $24 \mathrm{~m}$ above ground level, and took just under $4 \mathrm{~min}$ to span this range. From these measurements, an accurate profile of size segregated particle number counts for the lower to mid-canopy was obtained whereas the fixed monitors were used to provide longer term diurnal variation.

\subsection{Biological particle measurements}

Biological aerosol concentration size distributions were measured using a Wide Issue Bioaerosol Spectrometer (WIBS, Model 3, University of Hertfordshire). This is a real-time, single particle, dual-wavelength UV fluorescence spectrometer (Kaye et al., 2005; Foot et al., 2008), that detects particles in the range $0.5-20 \mu \mathrm{m}$. This instrument was located on the mast at ground level (close to the OPC inlet) and 14 full days of data were collected from it. Further details of this instrument and measurements may be found in Gabey et al. (2010).

\subsection{Aerosol composition}

Aerosol composition profiles were measured through a number of bag sampling experiments that were conducted during the second experimental phase. Ambient air was sampled simultaneously from the heights of each platform on the measurement tree through $40 \mathrm{~m} \mathrm{1/4}$ inch OD stainless steel tubing. The air was sampled into 1001 Teflon bags by evacuating the airtight housing in which they were contained, negating aerosol loss through the vacuum pump. Bags were inflated over a period of approximately $10 \mathrm{~min}$ before being sealed and transported to a High Resolution Time of Flight Aerodyne Aerosol Mass Spectrometer (HR-ToF-AMS; DeCarlo et al., 2006), located at the base of the GAW tower. The HR-ToF-AMS provides quantitative, chemically speci- ated aerosol loadings as well as additional mass spectral information of non-refractory aerosol particles in the size range $60-700 \mathrm{~nm}$. The bags were sampled sequentially in a random order with the HR-ToF-AMS until aerosol levels had decreased to low levels due to impaction on the bag, a period of around two hours. This allowed 2-3 10 min samples from each bag. The HR-ToF-AMS has a low flow rate of around $1.3 \mathrm{cc} \mathrm{min}-1$ and did not adversely affect the fill level of the bag. The decay of organic and sulphate aerosols, the two most abundant aerosol species, were fitted exponentially for each bag. The fits were extrapolated back to the time of sampling (around $40 \mathrm{~min}$ before measurement on the HR-ToFAMS), allowing an estimate of speciated aerosols loadings as a function of height within the canopy and trunk space.

Theoretical calculations (see Brockman, 2001) suggested that the aerosol losses in the inlet were small $(<1 \%)$ in the size range of the HR-ToF-AMS. In any case, the difference in residence times of the inlet $(4 \mathrm{~s})$ compared to the bags ( $40 \mathrm{~min}$ to $2 \mathrm{~h}$ ) means that it is the bags that are important in terms of aerosol losses.

\subsection{Boundary layer wind and turbulence}

Profiles of three-dimensional wind speed, turbulence statistics, aerosol and cloud backscatter were measured using a portable near IR pulsed Doppler lidar (a Halo-Photonics system). This was located approximately $200 \mathrm{~m}$ from, and $20 \mathrm{~m}$ below, the in-canopy site, and continuous measurements were available during the first phase only. The lidar was operated with 100 range gates at a resolution of $30 \mathrm{~m}$. Raw velocity and return power data were integrated every 30 min to derive signal to noise, backscatter coefficient and cloud and fog layer presence. Typical velocity resolutions are quoted as several $\mathrm{cm} \mathrm{s}^{-1}$ depending on signal to noise levels. A full description of the lidar measurements and results is given by Pearson et al. (2010).

\section{Results and discussion}

\subsection{Energy budget above and below canopy}

Figure 2 shows the diurnal variation in sensible heat flux both above the canopy (as measured from the GAW tower) and in the trunk space. Above the canopy, the pattern was as 


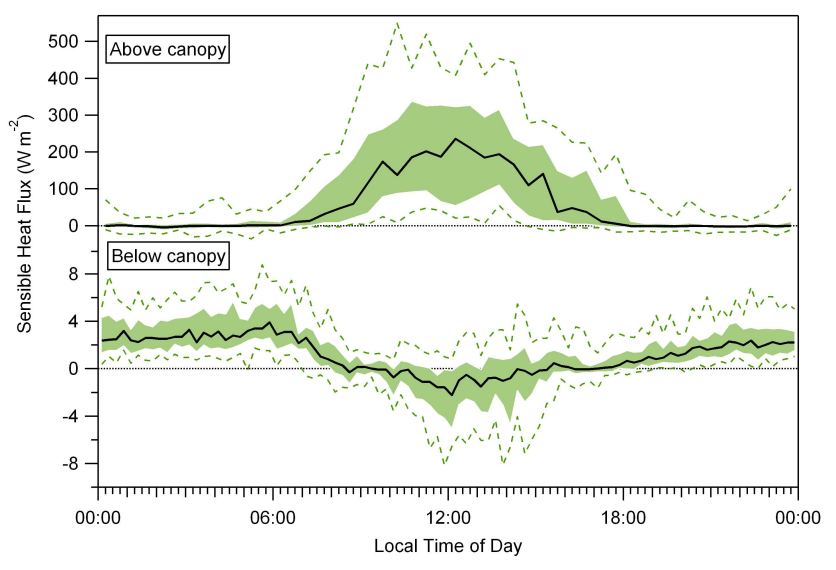

Fig. 2. Diurnal variation of sensible heat flux above the canopy (at the GAW tower) and in the trunk space. Shown are the median values at given times of day (black line), inter-quartile ranges (green shaded region) and 10th and 90th percentiles (dashed lines).

expected, with higher upward fluxes during the day, reducing to around zero overnight, although it is likely that at nighttime the GAW tower became decoupled from the canopy and that heat fluxes at the canopy top were actually more negative during night than is reflected in these measurements. This is consistent with the analysis of the heat flux measured within the canopy, close to canopy top (Helfter et al., 2010). The day-to-day variability was due to differences in cloud and rainfall conditions. Below the canopy, fluxes were much smaller and the largest positive fluxes were observed at night (due to radiative cooling in the upper canopy), with daytime fluxes around zero or negative in the middle of the day. This is consistent with measurements made in other tropical rainforests (Allen et al., 1972; Pinker and Holland, 1988; Kruijt et al., 2000). Kruijt et al. (2000) observed that the space within the canopy was largely stable during the day and only weakly unstable at night in the lower parts of the trunk space. Similarly, the canopy and trunk space in Borneo was mainly unstable at night and neutral or stable during the day. Above the canopy, the opposite was true in both studies, indicating persistent decoupling between above canopy and the trunk space in terms of turbulent parameters. This would have had the effect of suppressing transport into, and out of, the rainforest canopy, and so has implications for the exchange of gases and particles out of the canopy. During measurements in the Amazon, Fitzjarrald et al. (1990) found that the canopy removed high frequency turbulent fluctuations, while passing lower frequencies. This is consistent with the observation that turbulence within plant canopies scales with canopy height, which is large for tropical vegetation (e.g. Finnigan, 2000). Therefore, transport through the canopy will depend on large scale events. Nocturnal exchange has also been shown to occur under certain conditions (Fitzjarrald and Moore, 1990).

\subsection{Above canopy particle concentrations and fluxes}

A comparison between the ambient data obtained by the CPC models 3010 and 3025A showed no difference other than a systematic offset, implying that particles with diameters less than $10 \mathrm{~nm}$ were not observed. Measurements in the Amazon also did not observe particles in this size range, suggesting a lack of local nucleation (Zhou et al., 2002). Therefore the analysis will concentrate on data from the CPC 3010. Figure 3 shows the diurnal cycle of particle number concentration and flux at the GAW tower. Local fluxes at the tower were generally small overnight, with larger fluxes, both up and down, during the day. Of particular note are the apparent upward fluxes seen during the morning on some days, peaking to median values of around 400 particles $\mathrm{cm}^{-2} \mathrm{~s}^{-1}$ between 09:00 and 10:00 local time. These occurred on around $80 \%$ of the days during the campaign. Ahlm et al. (2009) observed a similar morning peak in particle number fluxes in the Amazon rainforest in Brazil. The peak in particle fluxes observed here occurred as the mixed layer was growing in the morning, and the fluxes reduced again once the mixing height reached its maximum (see Fig. 3). These fluxes may be attributed to venting of the nocturnal boundary layer as it breaks up in the morning below the height of the measurements on the GAW tower, and as the mixed layer grows. Rejection of non-stationary fluxes (see Sect. 2.2) did not fully remove the upward fluxes, however the peak appears slightly earlier (between 08:30 and 09:00 local time). This may be because after this time, the conditions are changing too rapidly to be considered stationary. It must be noted that the lidar measurements were made down in a valley, near the in-canopy site, about $1.2 \mathrm{~km}$ away from, and approximately $270 \mathrm{~m}$ lower than the CPC fluxes (see Fig. 1). While representative of the larger area which governs the exchange between the canopy and the air above, the mixing heights derived from the lidar data may therefore not be exactly accurate of the structure above Bukit Atur itself, particularly at night (Pearson et al., 2010).

Figure 4 shows the size distribution recorded by the DMPS above the canopy over the second measurement phase. A dominant mode was consistently seen at $50 \mathrm{~nm}$, with evidence of another mode around $150 \mathrm{~nm}$. The size distribution did not vary significantly during the upward flux events, even when an increase of particle number concentration was seen. This suggests either that the particles emitted from below were similar in size to those into which they were being mixed, or the upward fluxes were not large enough to significantly impact on the properties or concentration of the aerosol population. At around the same time as the observed upward fluxes, there is an apparent increase in the particle number concentration. However this was not found to be significant, even when only considering days on which the upward fluxes were seen. This is because the upward fluxes were not always associated with an increase in particle number concentration. 


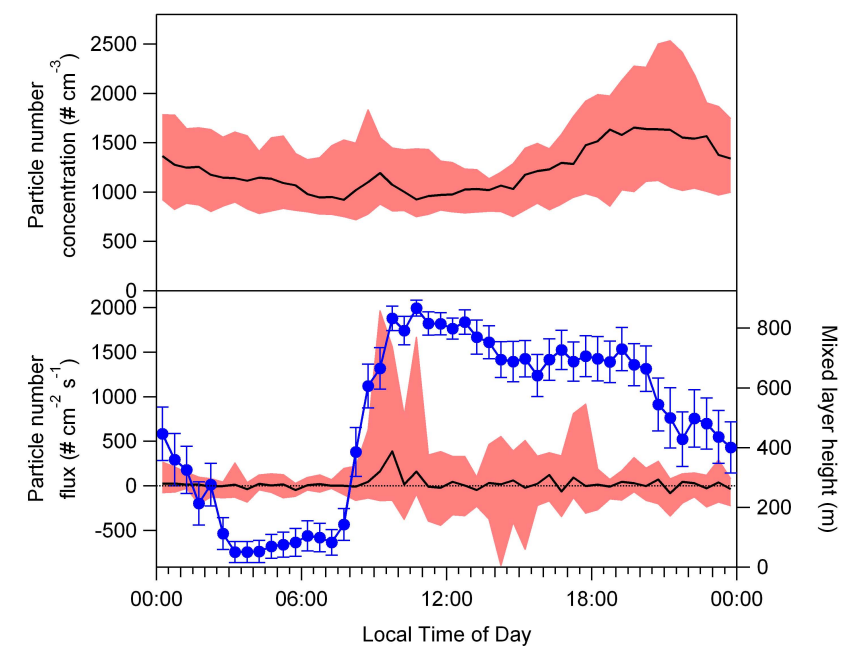

Fig. 3. Diurnal variation of particle number concentration (top) and flux (bottom) measured at the GAW tower plotted as median values at given times of day (black line) and the inter-quartile ranges (red shaded region). Also shown is the diurnal average mixed layer height derived from the lidars aerosol backscatter data (blue trace). The zero line on the particle number flux axis also marks the height of the flux measurements on the GAW tower above the lidar measurements on the mixed layer height axis. Error bars are standard error.

\subsection{Fog deposition}

The PVM-100 at $32 \mathrm{~m}$ on the tower was not located sufficiently close to the anemometer for reliable eddy covariance measurements. However, an estimate of the fog water deposition may be derived under the assumption that the laminar boundary layer resistance and canopy uptake resistance are small compared with the resistance for turbulent transport, by dividing LWC by the aerodynamic resistance, $r_{a}$ :

$F_{\mathrm{LWC}}=\mathrm{LWC} / r_{a}$

where

$r_{a}(z-d)=\frac{u(z-d)}{u_{*}^{2}}-\frac{\psi_{H}(z / L)-\psi_{M}(z / L)}{\kappa u_{*}}$

at a given height $z-d$, where $z$ is the measurement height, $d$ the zero-plane displacement height, $u$ is the wind speed, $u_{*}$ is the friction velocity, $L$ is the Obukhov length (a measure of stability), $\kappa$ is the von Kármán constant (0.41), and $\psi_{H}$ and $\psi_{M}$ are the integrated stability functions for heat and momentum, respectively, which may be approximated by the analytical solutions derived by Paulson (1970) (see Garland, 1977). Using this method, it was estimated that a total of $1.6 \mathrm{~mm}$ of fog was deposited to the rainforest over the period from 14 April until 3 May. This is much lower than the total rainfall during the same period of $277 \mathrm{~mm}$ (although the rainfall was significantly higher than usual for that time of year; Hewitt et al., 2010).

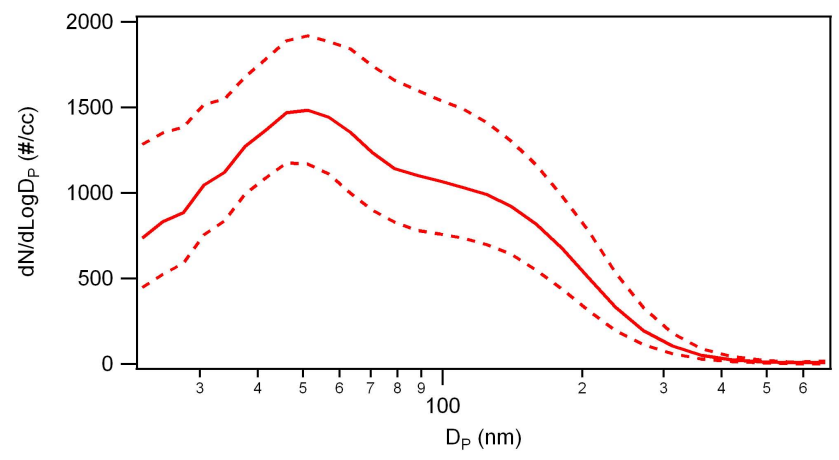

Fig. 4. Particle size distribution as measured with the DMPS at the GAW tower. The graph shows median (solid line) and inter-quartile range (dashed line) for the period 21st June to 24th July 2008.

This is likely to be a lower limit as the estimate only includes turbulent flux, and also because of its position at $32 \mathrm{~m}$ on the GAW tower. There was less fog at this height on the Bukit Atur ridge than at canopy height in the surrounding valleys. Lidar measurements (Pearson et al., 2010) show that the frequency of fog occurrence is around $60 \%$ in the valley between the hours of 02:00 a.m. to 06:00 a.m. local time, while the PVM-100 measurements suggest that fog reaches the height of the GAW tower only $11 \%$ of the time during the same early morning period (based on a threshold LWC of $20 \mathrm{mg} \mathrm{m}^{-3}$ ). Therefore the actual deposition rate is likely to be higher. This warrants further investigation as fog has been found to be a significant pathway for the deposition of nutrients and other atmospheric constituents to forests in other parts of the world (Fowler et al., 1989; Liu et al., 2004).

\subsection{In-canopy aerosol profiles}

The OPC data from the winch system was separated into $2 \mathrm{~m}$ height bins and averaged up to give hourly profiles of size-segregated aerosol number concentrations to a height of $24 \mathrm{~m}$ in the canopy. These were then separated further into submicron $\left(0.3-1 \mu \mathrm{m} ; N_{D_{p}<1}\right)$ and supermicron $(1-20 \mu \mathrm{m}$; $\left.N_{D_{p}>1}\right)$ size ranges as these were seen to exhibit different behaviour. Both are plotted as diurnal averages in Fig. 5, showing a significant diurnal variation in the supermicron aerosol profile. Number concentrations in this size range began to increase with height shortly after sunset. This gradient increased throughout the night until about sunrise, when concentrations at all heights dropped to less than $10^{3} \mathrm{~L}^{-1}$ for the rest of the morning. Fog formation frequently occurs at the top of, and above, rainforest canopies at night and in the early morning due to high relative humidity at these times (typically more than $80 \%$ both above and below canopy in this case). Lidar measurements show high backscatter values in the early morning, indicative of thick fog up to a height of around $200 \mathrm{~m}$ (Pearson et al., 2010). The diurnal variation in supermicron particles observed towards the top of the canopy 


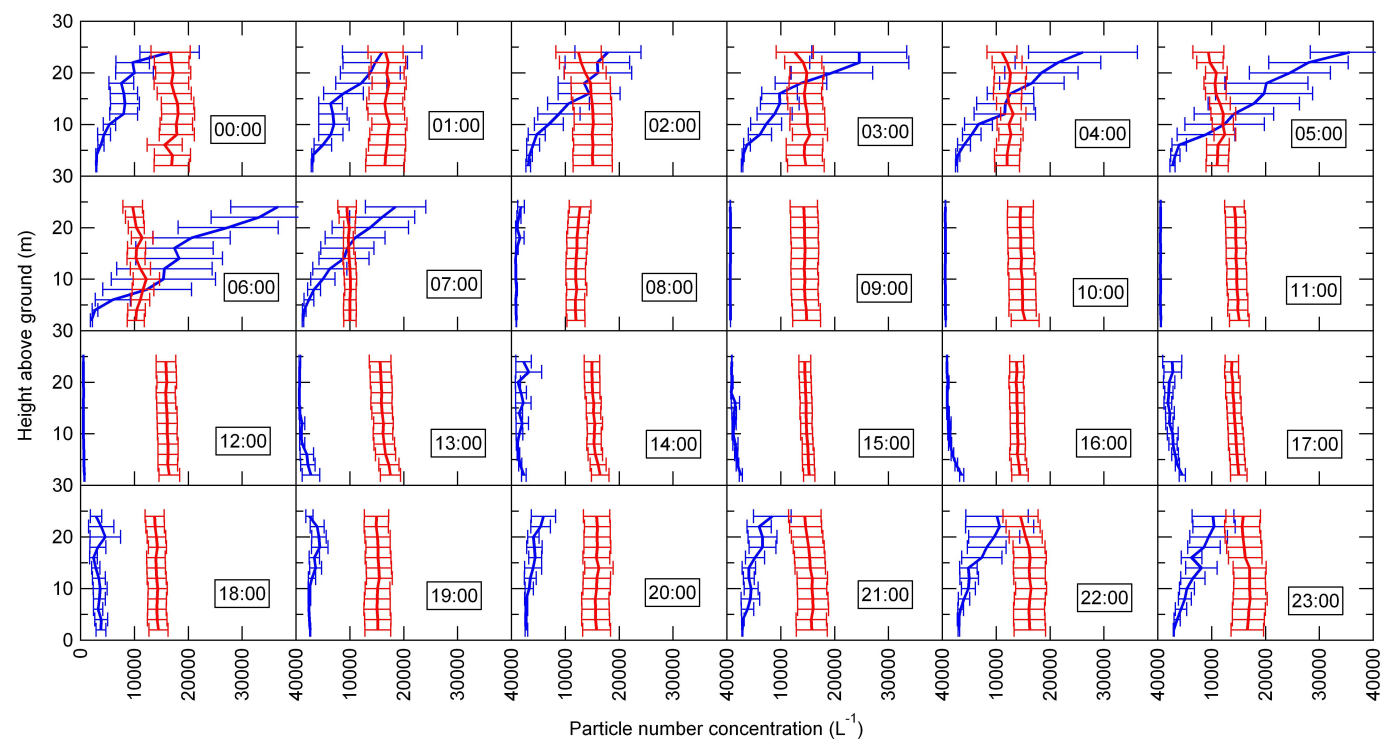

Fig. 5. Diurnally averaged hourly profiles of aerosol number concentration within the canopy and trunk space. These are separated into submicron $(0.3-1 \mu \mathrm{m}$; red lines) and supermicron (1-20 $\mu \mathrm{m}$; blue lines) within the range of the GRIMM aerosol spectrometer. Local (GMT+8) start time of each hourly period is shown. Error bars represent one standard error.

therefore appear to be due to late-night/early-morning fog formation at the canopy top, penetrating some way into the canopy itself.

Figure 6a shows this process occurring on a daily basis from the fixed OPC at a height of $16 \mathrm{~m}$ on the measurement tree. In this period, the nocturnal increase in $N_{D_{p}>1}$ coincided with a decrease in $N_{D_{p}<1}$. The diurnal pattern in submicron particles in the canopy (shown in Fig. 7a) also shows an overnight decrease, particularly from around midnight onwards. This suggests growth of these particles to the larger sizes and hence activation as fog droplets. The lower size limit of the OPC is $300 \mathrm{~nm}$ and it is likely that large numbers of particles below this size also become activated and grow. This would account for the imbalance between the increase in $N_{D_{p}>1}$ and the decrease in $N_{D_{p}<1}$ due to activation. The source of these submicron particles is uncertain, however as discussed in the next section, they are likely representative of regional scale aerosols.

Supermicron particles at ground level showed similar enhanced concentrations overnight, but to a lesser extent than higher up in the canopy, and this can be seen more clearly in Fig. 7b. It can also be seen from this figure, however, that the highest concentrations were observed during the afternoon, increasing from about 13:00 to a peak at around sunset of around $5 \times 10^{3} \mathrm{~L}^{-1}$. This pattern is consistent with the WIBS data, which also showed that Fluorescent Primary Biological Aerosol Particles (FBAP) account for, on average, 55\% of particles in the size range $0.8-20 \mu \mathrm{m}$ at the forest floor (Gabey et al., 2010). Figure 8 shows the size distribution of FBAP and non-FBAP number concentrations as measured with the WIBS, and illustrates how FBAP dominates the su- permicron aerosol population in the trunk space. Both instruments report an aerosol size distribution in the supermicron range at the forest floor with a consistent mode between 2$3 \mu \mathrm{m}$. The nature of these particles is discussed in more detail by Gabey et al. (2010). The OPC profile measurements in Fig. 5 suggest that the afternoon increase in these particles only extended to a height of about $10 \mathrm{~m}$ and that it was greatest at ground level. This may imply that, during daytime at least, FBAP activity only occurred in the lowest part of the trunk space, although it could also be due to the fact that the turbulence is lowest close to the ground, resulting in the build up of concentrations. It is not clear how high this extended during night time due to the increased cloud droplet number concentrations in the upper parts of the canopy, but also because the reduced stability of the air below the canopy at night would have led to greater mixing (see above). WIBS measurements above canopy showed that the FBAP contribution to total particle number concentrations in the size range $0.8-20 \mu \mathrm{m}$ was only around $28 \%$. $N_{D_{p}>1}$ (measured with the OPC) decreased exponentially from just before sunrise, coinciding with the cessation of the FBAP emission processes (Gabey et al., 2010). The supermicron particles are most likely removed from the canopy space by sedimentation and impaction (e.g. Pryor et al., 2008), and the mean e-folding time for this decay was calculated to be approximately $1.5 \mathrm{~h}$. Assuming a ceiling for FBAP activity of $10 \mathrm{~m}$, this implies a mean deposition velocity of around $2 \mathrm{~mm} \mathrm{~s}^{-1}$. If the FBAP activity extends to greater heights overnight, say $25 \mathrm{~m}$ (the minimum height of the canopy top), the mean deposition velocity is around $4.5 \mathrm{~mm} \mathrm{~s}^{-1}$. 


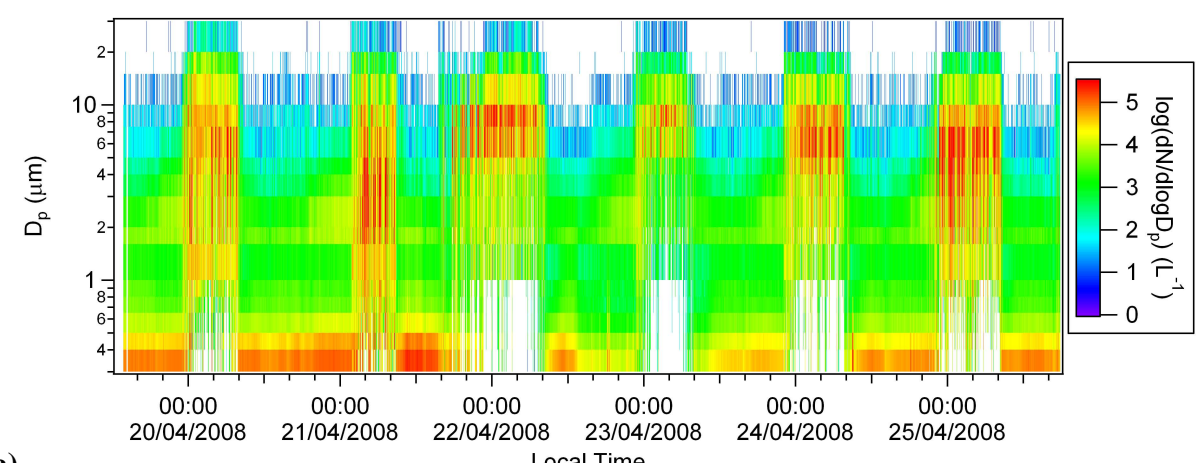

(a) Local Time

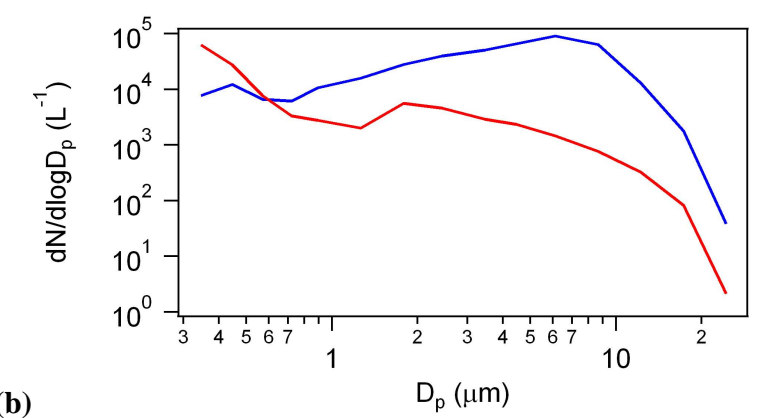

Fig. 6. (a) Time-series of size distributions measured with the GRIMM OPC on the $16 \mathrm{~m}$ platform within the canopy. (b) The size distributions averaged over this time-series for periods of fog (blue) and no fog (red).

No significant gradient in submicron particles was observed inside the canopy at any time of day and strong correlations were found between the number concentrations at various heights. This implies that submicron particles were uniformly dispersed throughout the canopy and trunk space at all times. Guyon et al. (2003) also found fine particles $\left(D_{p}<2.0 \mu \mathrm{m}\right)$ to be well mixed throughout the canopy and trunk space in the Amazon (although they observe different behaviours for different trace elements, depending on their source). In this work, however, a diurnal pattern was seen in which number concentrations were higher in the middle of the day (Fig. 7a), rising from around 08:00 to a late morning peak. These concentrations remained relatively steady over the afternoon and evening before decreasing from about midnight until sunrise. This pattern occurred at all measurement heights, however the daytime increase was not observed every day. Processes governing the submicron particle number concentrations within the canopy and trunk space are discussed in the next section.

\subsection{Interpretation of particle concentrations above and below canopy}

Comparisons were made between the APS measuring at $33 \mathrm{~m}$ on the GAW tower and the OPC on the mast on the forest floor. No relationship could be found between the two sites for the supermicron particle size range. However, throughout the experiment, certain features in the submicron $(0.5-$
$1.0 \mu \mathrm{m})$ particle time-series were present at both sites. This can be seen in Fig. 9, which also reveals that while these features were sometimes seen at both sites simultaneously, there was also often a delay time between detection at the GAW tower and detection in the trunk space (with the above canopy measurement always preceding). A cross-correlation was performed on the two one-minute time-series in order to determine what the delay time $(\Delta t)$ was at any given time. This was found to range from zero (simultaneous measurements) to as much as three hours. Figure 10 shows how $\Delta t$ varies as a function of time of day by showing the median diurnal variation (as well as the interquartile range) of $\Delta t$ over the measurement period. It suggests that, generally, $\Delta t$ was lowest during the middle of the day, between 11:00 and 15:00, when it was mostly less than 30 min.

During this daytime period of relatively low $\Delta t$, a strong correlation is seen between particle number concentrations above canopy and in the trunk space $\left(r^{2}=0.64\right)$. Thus it seems that the morning rise in submicron particle concentration seen at the forest floor in Fig. 7a (which, due to the lack of gradient observed from the OPC on the winch, can be considered representative of the trunk space) is due to an influx of particles from above the canopy. When this influx becomes less efficient at night, there is little or no correlation, and on average the trunk space concentration begins to decrease while it increases above canopy (see Fig. 3). 

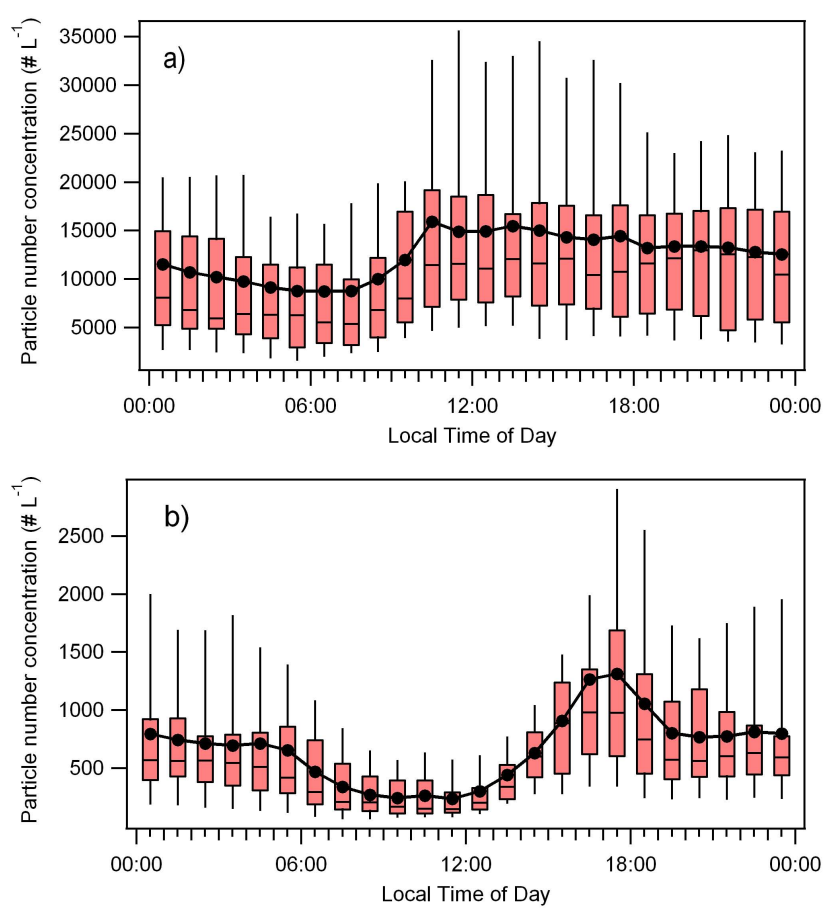

Fig. 7. Diurnal variation of (a) submicron $(0.3-1 \mu \mathrm{m})$, and (b) supermicron $(1-20 \mu \mathrm{m})$ particle number concentration as measured by the OPC on the mast near the forest floor. The black markers and lines show the means, while the boxes represent the inter-quartile range and the whiskers represent the $10 \%$ to $90 \%$ range.

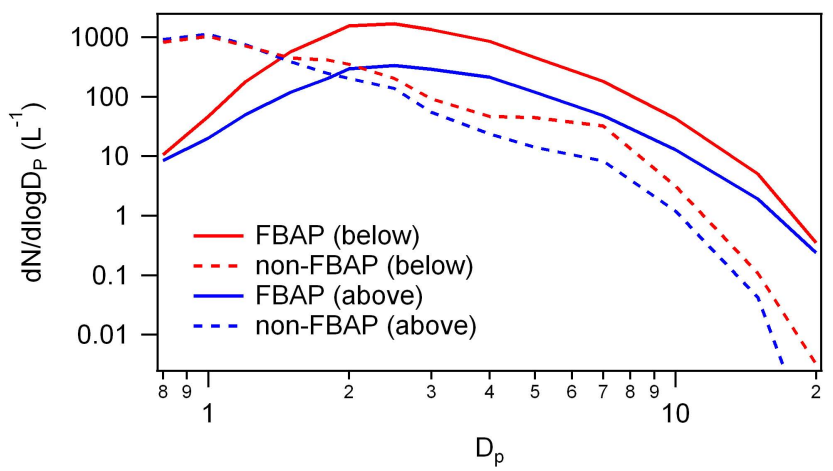

Fig. 8. Mean number size distributions of FBAP and non-FBAP in the range $0.8-20 \mu \mathrm{m}$, as measured with the WIBS (see Gabey et al., 2010).

Further evidence of particle transfer from above canopy to the trunk space can be seen in the results of the in-canopy bag samples (Fig. 11). As there were only a few of these samples made, it is impossible to make firm conclusions about the aerosol mass loadings of the individual chemical compounds and their profiles within the rainforest canopy and trunk space. Nevertheless, the ratios of sulphate to organics are generally consistent with the AMS measurements made above the canopy at the GAW site, as seen in the figure.

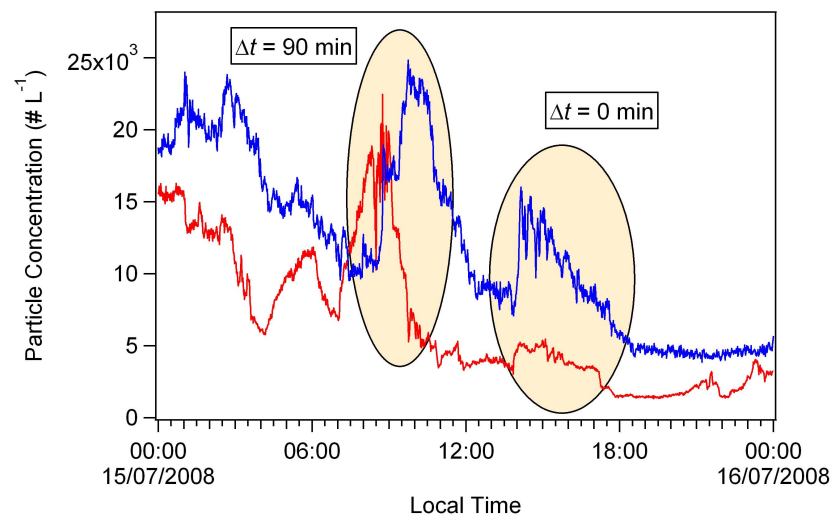

Fig. 9. Time-series of submicron particle concentrations above canopy from the APS (red trace) and in the trunk space from the OPC (blue trace) illustrating a relationship between the measurements at the two sites and the variation in delay time $(\Delta t)$.

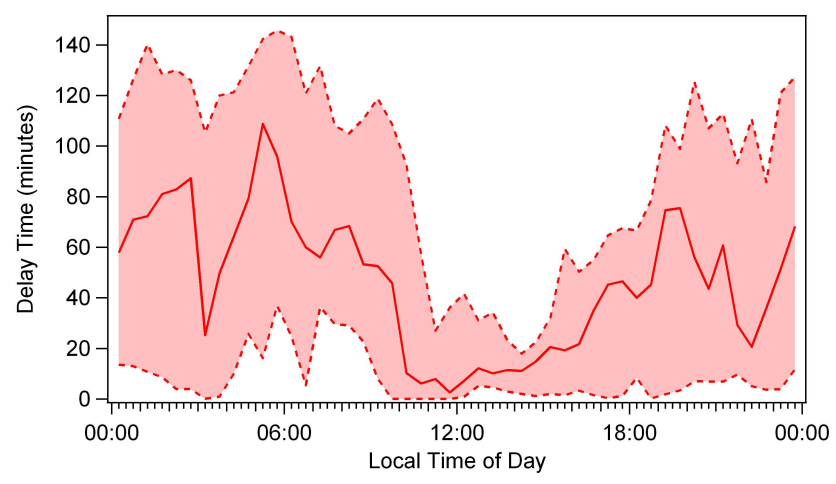

Fig. 10. Diurnal variation in delay time calculated from the correlation between above canopy and trunk space submicron particle measurements. Solid lines represent the median values, while the dashed lines and shaded area show the inter-quartile ranges.

When the ratios do not seem to match so well, on the 27 June, correlations between above canopy and the trunk space were very poor with large $\Delta t$.

This would seem at first to contradict the conclusion of Sect. 3.1 that the region above the canopy is decoupled from the trunk space based on the different behaviour of the sensible heat fluxes. However, as already discussed, transfer of atmospheric constituents through the canopy can occur due to large-scale, intermittent turbulent events on timescales of a few minutes (Gao et al., 1989; Fitzjarrald et al., 1990; Rummel et al., 2002), whereas sensible heat flux is dominated by high frequency turbulence. Figure 12 shows the quadrant plots (joint probability distributions of $w^{\prime}$ and $u^{\prime}$; see, e.g. Finnigan, 2000) and spectra from two different episodes: (a) when there was no correlation between above canopy and trunk space particle measurements; and (b) when the correlation was strong and $\Delta t$ was short (a few minutes). When particle measurements do not correlate, the 


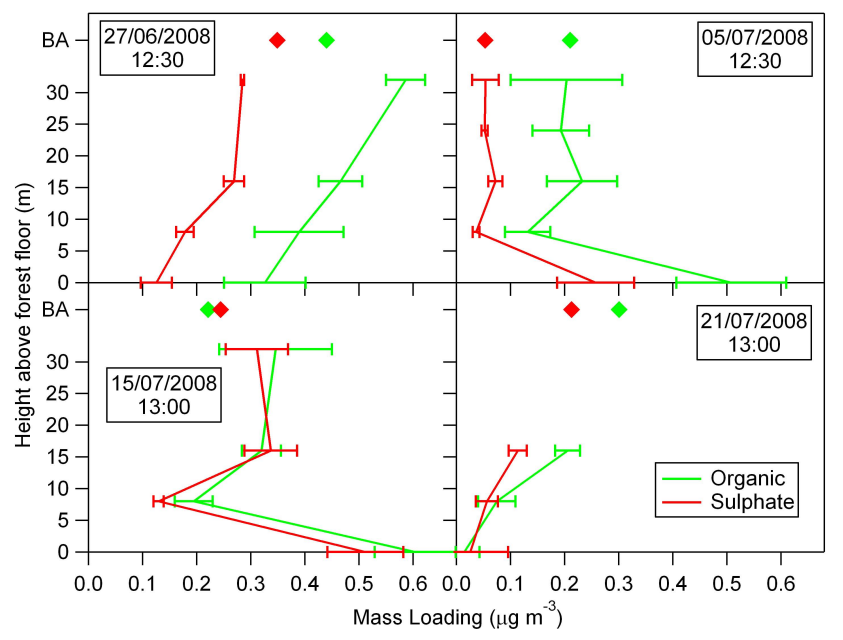

Fig. 11. Speciated aerosol concentration profiles within the canopy and trunk space from bag samples, analysed with the AMS. Values measured concurrently by the AMS above canopy at Bukit Atur are marked as diamonds and labelled "BA" on the left axis. Times are approximate local times at the start of sampling.

quadrant analysis shows no significant features, and no particular quadrant is favoured. The power spectra for $w\left(S_{w}\right)$ and the co-spectra for $w$ and temperature $\left(\mathrm{Co}_{w T}\right)$ follow the theoretical power laws in the inertial subrange (Kaimal et al., 1972). On the other hand, when particle transfer is clearly occurring, the quadrant plots show a weak correlation between $w^{\prime}$ and $u^{\prime}$, concentrating in the top left and bottom right quadrants, which represent "ejections" (upward moving air) and "sweeps" (fast, downward gusts), respectively (Finnigan, 2000). The spectra and co-spectra show a reduction of power in the inertial subrange, with additional energy apparently being created at higher frequencies. This may be due to wake effects of the canopy elements transferring energy from the larger eddies directly to the higher frequencies (Finnigan, 2000). This process is evident to some extent in Fig. 12a, but is most prominent in Fig. 12b, when the particle measurements correlate. A time-series of the power spectra for $w$ (Fig. 13) shows that these spectra varied with a very regular diurnal pattern. The pattern seen in Fig. 13 occurred on every day of measurement without exception. The spectrum $\left(S_{w}\right)$ shown in Fig. 12a is typical of night-time conditions, while the additional energy at higher frequencies, as seen in the spectrum $\left(S_{w}\right)$ in Fig. $12 \mathrm{~b}$, is seen more during the daytime, between around 08:00 and 19:00. These times are approximately coincident with the reduction in $\Delta t$ seen in Fig. 10 (although the reduction may begin a little later in the morning), supporting the idea that particle transfer through the canopy is dependent on large scale processes. Similar patterns in spectra were observed by Kruijt et al. (2000), however their quadrant analysis does not show much correlation between $w^{\prime}$ and $u^{\prime}$ at the bottom of the canopy. It is not clear why these results differ from theirs.
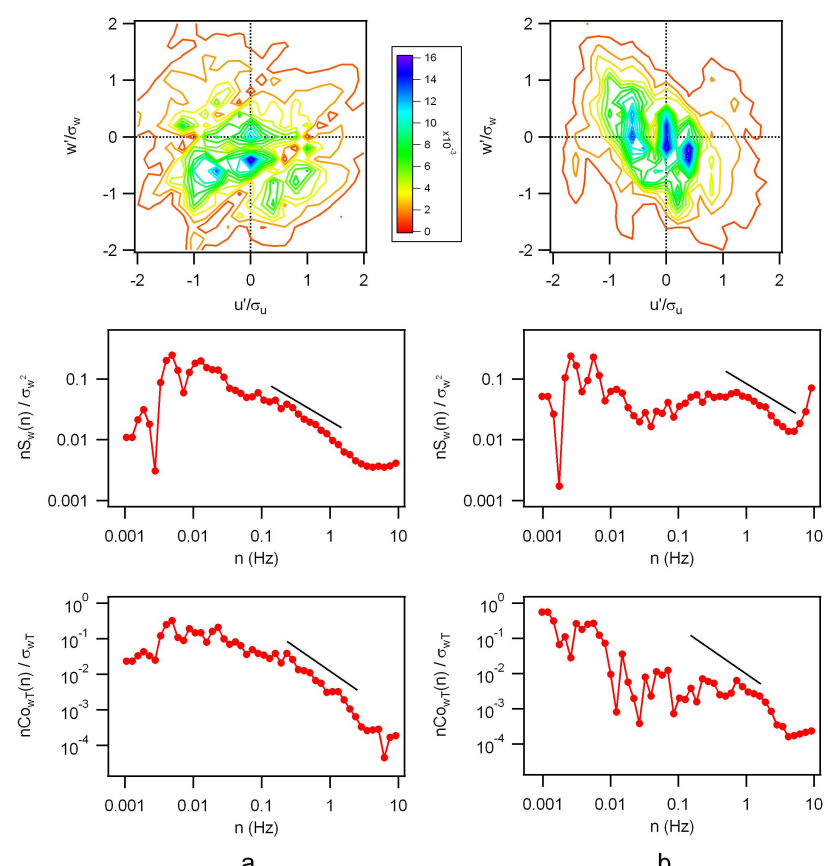

Fig. 12. Quadrant plots of normalised $u$ and $w$ fluctuations (top panels), frequency weighted power spectra of $w$ (middle panels) and co-spectra of $w$ and temperature (bottom panels) for groundlevel trunk space data taken at (a) 07:00 on the 16th July, and (b) 14:00 on the 15 th July 2008 . The solid black lines on the spectra and co-spectra represent the theoretical inertial subrange slopes of $n^{-2 / 3}$ and $n^{-4 / 3}$ respectively (Kaimal et al., 1972).

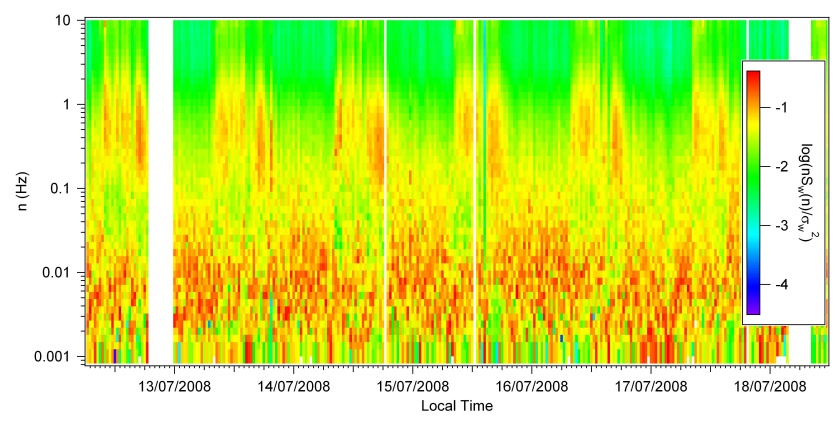

Fig. 13. A time-series of the frequency weighted power spectra of $w$.

The in-canopy transport mechanisms during this study are considered in more detail by Ryder et al. (2010) and Helfter et al. (2010) and will also be the subject of further study.

It should be noted that while common features in the submicron particle time-series were always seen above the canopy before or at the same time as they were seen in the trunk space, this does not imply that particle transfer only occurs down into the canopy. Due to the distance between the measurement sites, any changes in particle concentrations that were seen at both sites must have been a large 


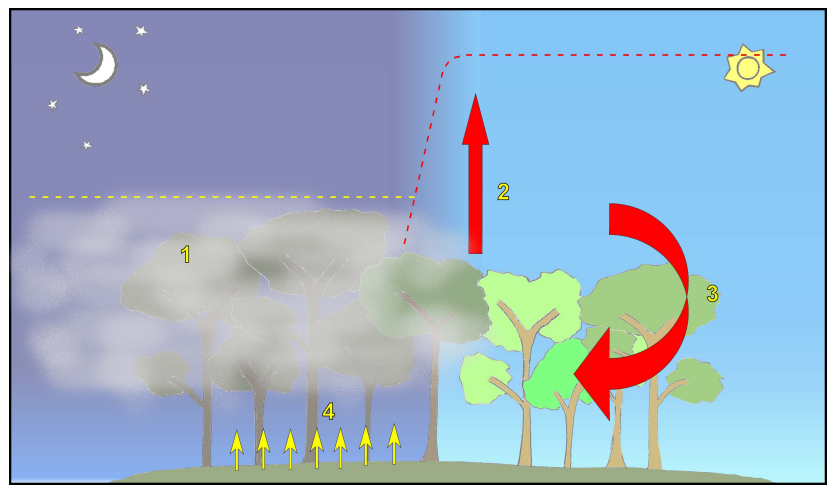

Fig. 14. A summary of the processes governing the particle number concentrations above and within the rainforest canopy. The yellow dashed line depicts the top of the stable nocturnal boundary layer, while the red dashed line marks the daytime mixed layer. The numbers mark the important processes observed here, which are discussed in the main text of Sect. 4.

scale event. Any particle emissions from the canopy space into the mixed layer would have therefore occurred on small scales, been quickly diluted into the larger mixed layer above canopy, and would therefore not have been registered by measurements at the GAW tower. Similarly, this analysis does not rule out the possibility of exchange of supermicron particles between above canopy and the trunk space. Such exchange is discussed in more detail by Gabey et al. (2010).

\section{Summary and conclusions}

Aerosol concentrations and fluxes were measured above and below a rainforest canopy in North-East Borneo. These measurements showed significant diurnal patterns at all levels that were consistent throughout the measurement period. These are summarised in Fig. 14. Overnight, a persistent decoupling between the canopy space and the overlying atmosphere resulted from a shallow nocturnal boundary layer. This also gave rise to the frequent appearance of fog at the canopy level (marked 1 in Fig. 14), as evident in the observation of the overnight increase in supermicron particles in the upper parts of the canopy. After sunrise, as the nocturnal boundary layer breaks up, the fog is rapidly burned off, resulting in a sharp drop in these supermicron particle number concentrations. Shortly afterwards, an upward flux of aerosols was seen above the canopy (2). It is likely that this flux is due to venting of aerosols from the nocturnal boundary layer as it breaks up.

Throughout the day, the stronger turbulence results in greater mixing, and coupling through the dense foliage of the canopy is able to occur through large-scale sporadic turbulent events (3). As a result, particles in the submicron range correlate strongest during these times. Therefore submicron aerosols throughout the canopy (which show no significant variation with height) may be considered representative of above canopy aerosols, at least during the day. This conclusion is further supported by aerosol composition measurements, which indicate that aerosols in the trunk space have similar composition to those above canopy. In this study, this process was seen in the submicron range of particles but can not be ruled out for larger particles. At ground level, below the canopy, number concentrations of supermicron particles correlate with co-located PBAP measurements, showing that biological aerosols dominate at this level. These aerosols peak in number concentration during the late afternoon and early evening, and remain high overnight (consistent with fungal spore release; 4 ).

Acknowledgements. The authors would like to thank the Malaysian and Sabah Governments for their permission to conduct research in Malaysia, the Malaysian Meteorological Department for access to the Bukit Atur Global Atmosphere Watch station, Waidi Sinun of Yayasan Sabah and his staff, Glen Reynolds and his staff at the Royal Society's Danum Valley Research Centre for all their assistance with the field work, and Nick Chappell and Brian Davison of Lancaster University for logistical support at the Danum Valley Field Centre. In addition we acknowledge Mhairi Coyle (CEH) for assembling the automated winch system, and Gavin Phillips (CEH) and Martin Irwin (Manchester) for their help with the installation of the in-canopy site. This research was funded by NERC under the OP3 (grant ref: NE/D002117/1) and ACES (grant ref: NE/E011233/1) projects. Support for the lidar and its deployment was provided by the NERC National Center for Atmospheric Measurement (NCAS) Facility for Ground based Atmospheric Measurements (FGAM). This is paper number 514 of the Royal Society's South East Asian Rainforest Research Programme.

Edited by: R. MacKenzie

\section{References}

Ahlm, L., Nilsson, E. D., Krejci, R., Mårtensson, E. M., Vogt, M., and Artaxo, P.: Aerosol number fluxes over the Amazon rain forest during the wet season, Atmos. Chem. Phys., 9, 9381-9400, doi:10.5194/acp-9-9381-2009, 2009.

Allen Jr., L. H.,, Lemon, E., and Müller, L.: Environment of a Costa Rican forest, Ecology, 53, 102-111, 1972.

Andreae, M. O., Artaxo, P., Brandão, C., Carswell, F. E., Ciccioli, P., da Costa, A. L., Culf, A. D., Esteves, J. L., Gash, J. H. C., Grace, J., Kabat, P., Lelieveld, J., Malhi, Y., Manzi, A. O., Meixner, F. X., Nobre, A. D., Nobre, C., Ruivo, M. d. L. P., Silva-Dias, M. A., Stefani, P., Valentini, R., von Jouanne, J., and Waterloo, M. J.: Biogeochemical cycling of carbon, water, energy, trace gases, and aerosols in Amazonia: The LBA-EUSTACH experiments, J. Geophys. Res., 107, 8066, doi:8010.1029/2001JD000524, 2002.

Artaxo, P., Maenhaut, W., Storms, H., and Grieken, R. V.: Aerosol characteristics and sources for the Amazon Basin during the wet season, J. Geophys. Res., 95, 16971-16985, 1990.

Artaxo, P., Gerab, F., Yamasoe, M. A., and Martins, J. V.: Fine mode aerosol composition at three long-term atmospheric mon- 
itoring sites in the Amazon Basin, J. Geophys. Res., 99, 2285722868, 1994.

Artaxo, P., Martins, J. V., Yamasoe, M. A., Procópio, A. S., Pauliquevis, T. M., Andreae, M. O., Guyon, P., Gatti, L. V., and Leal, A. M. C.: Physical and chemical properties of aerosols in the wet and dry seasons in Rhondnia, Amazonia, J. Geophys. Res., 107, 8081, doi:8010.1029/2001JD000666, 2002.

Brockman, J. E.: Sampling and transport of aerosols, in: Aerosol measurement - Principles, techniques, and applications (2nd edition), edited by: Baron, P. A. and Willeke, K., John Wiley \& Sons, New York, 2001.

DeCarlo, P. F., Kimmel, J. R., Trimborn, A., Northway, M. J., Jayne, J. T., Aiken, A. C., Gonin, M., Fuhrer, K., Horvath, T., Docherty, K. S., Worsnop, D. R., and Jimenez, J. L.: Field-deployable, high resolution, time-of-flight aerosol mass spectrometer, Anal. Chem., 78, 8281-8289, 2006.

Farmer, D. K., Kimmel, J. R., Nemitz, E., Phillips, G., Docherty, K., Chen, Q., Martin, S., Cubison, M., and Jimenez, J.: A new approach to chemically-speciated submicron aerosol fluxes over tropical and temperate forests, American Geophysical Union, Fall Meeting 2008, San Francisco, USA, 15-19 December 2008, abstract A51H-0204, 2008.

Finnigan, J.: Turbulence in plant canopies, Annu. Rev. Fluid Mech., 32, 519-571, 2000.

Fitzjarrald, D. R. and Moore, K. E.: Mechanisms of nocturnal exchange between the rain forest and the atmosphere, J. Geophys. Res., 95, 16839-16850, 1990.

Fitzjarrald, D. R., Moore, K. E., Cabral, O. M. R., Scolar, J., Manzi, A. O., and de Abreu, L. D., Sá: Daytime turbulent exchange between the Amazon forest and the atmosphere, J. Geophys. Res., 95, 16825-16838, 1990

Foken, T. and Wichura, B.: Tools for quality assessment of surfacebased flux measurements, Agr. Forest Meteorol., 79, 83-105, 1996.

Foken, T.: Micrometeorology, Springer-Verlag, Berlin, 306 pp., 2006.

Foot, V. E., Kaye, P. H., Stanley, W. R., Barrington, S. J., Gallagher, M., and Gabey, A.: Low-cost real-time multiparameter bio-aerosol sensors, Proc. SPIE, 7116, 71160I, doi:10.1117/12.800226, 2008.

Fowler, D., Cape, J. N., and Unsworth, M. H.: Deposition of atmospheric pollutants on forests, Philos. T. Roy. Soc. London B, 324, 247-265, 1989.

Gabey, A. M., Gallagher, M. W., Whitehead, J., Dorsey, J. R., Kaye, P. H., and Stanley, W. R.: Measurements and comparison of primary biological aerosol above and below a tropical forest canopy using a dual channel fluorescence spectrometer, Atmos. Chem. Phys., 10, 4453-4466, doi:10.5194/acp-10-4453-2010, 2010.

Gao, W., Shaw, R. H., and Paw U, K. T.: Observation of organized structure in turbulent flow within and above a forest canopy, Bound.-Lay. Meteorol., 47, 349-377, 1989.

Garland, J. A.: The dry deposition of sulphur dioxide to land and water surfaces, Proc. Roy. Soc. Lond. A, 354, 245-268, 1977.

Gerber, H.: Direct measurement of suspended particulate volume concentration and far-infrared extinction coefficient with a laserdiffraction instrument, Appl. Optics, 30, 4824-4831, 1991.

Guyon, P., Graham, B., Roberts, G. C., Mayol-Bracero, O. L., Maenhaut, W., Artaxo, P., and Andreae, M. O.: Incanopy gradients, composition, sources, and optical properties of aerosol over the Amazon forest, J. Geophys. Res., 108, 4591, doi:4510.1029/2003JD003465, 2003.

Heim, M., Kasper, G., Reischl, G. P., and Gerhart, C.: Performance of a New Commercial Electrical Mobility Spectrometer, Aerosol Sci. Tech., 38(S2), 3-14, 2004.

Hewitt, C. N., Lee, J. D., MacKenzie, A. R., Barkley, M. P., Carslaw, N., Carver, G. D., Chappell, N. A., Coe, H., Collier, C., Commane, R., Davies, F., Davison, B., DiCarlo, P., Di Marco, C. F., Dorsey, J. R., Edwards, P. M., Evans, M. J., Fowler, D., Furneaux, K. L., Gallagher, M., Guenther, A., Heard, D. E., Helfter, C., Hopkins, J., Ingham, T., Irwin, M., Jones, C., Karunaharan, A., Langford, B., Lewis, A. C., Lim, S. F., MacDonald, S. M., Mahajan, A. S., Malpass, S., McFiggans, G., Mills, G., Misztal, P., Moller, S., Monks, P. S., Nemitz, E., Nicolas-Perea, V., Oetjen, H., Oram, D. E., Palmer, P. I., Phillips, G. J., Pike, R., Plane, J. M. C., Pugh, T., Pyle, J. A., Reeves, C. E., Robinson, N. H., Stewart, D., Stone, D., Whalley, L. K., and Yin, X.: Overview: oxidant and particle photochemical processes above a south-east Asian tropical rainforest (the OP3 project): introduction, rationale, location characteristics and tools, Atmos. Chem. Phys., 10, 169-199, doi:10.5194/acp-10169-2010, 2010

Helfter, C., Phillips, G. J., Coyle, M., Di Marco, C. F., Langford, B., Whitehead, J., Dorsey, J. R., Gallagher, M. W., Sei, E. Y., Fowler, D., and Nemitz, E.: Momentum and heat exchange above South East Asian rainforest in complex terrain, Atmos. Chem. Phys. Discuss., in preparation, 2010.

Horst, T. W.: A simple formula for attenuation of eddy fluxes measured with first-order-response scalar sensors, Bound.-Lay. Meteorol., 82, 219-233, 1997.

Intergovernmanetal Panel on Climate Change (IPCC): Climate change 2007: The fourth assessment report of the Intergovernmental Panel on Climate Change, Cambridge University Press, Cambridge, 2007.

Järvi, L., Rannik, Ü., Mammarella, I., Sogachev, A., Aalto, P. P., Keronen, P., Siivola, E., Kulmala, M., and Vesala, T.: Annual particle flux observations over a heterogeneous urban area, Atmos. Chem. Phys., 9, 7847-7856, doi:10.5194/acp-9-7847-2009, 2009.

Kaimal, J. C., Wyngaard, J. C., Izumi, Y., and Coté, O. R.: Spectral characteristics of surface-layer turbulence., Q. J. Roy. Meteorol. Soc., 98, 563-589, 1972.

Kavouras, I. G., Mihalopoulas, N., and Stephanou, E. G.: Formation of atmospheric particles from organic acids produced by forests, Nature, 395, 683-686, 1998.

Kaye, P. H., Stanley, W. R., Hirst, E., Foot, E. V., Baxter, K. L., and Barrington, S. J.: Single particle multichannel bio-aerosol fluorescence sensor, Optics Express, 13, 3583-3593, 2005.

Kruijt, B., Malhi, Y., Lloyd, J., Nobre, A. D., Miranda, A. C., Pereira, M. G. P., Culf, A., and Grace, J.: Turbulence statistics above and within two Amazon rain forest canopies, Bound.-Lay. Meteorol., 94, 297-331, 2000.

Kulmala, M., Toivonen, A., Mäkelä, J. M., and Laaksonen, A.: Analysis of the growth of nucleation mode particles observed in Boreal forest, Tellus, 50B, 449-462, 1998.

Langford, B., Misztal, P. K., Nemitz, E., Davison, B., Helfter, C., Pugh, T. A. M., MacKenzie, A. R., Lim, S. F., and Hewitt, C. N.: Fluxes and concentrations of volatile organic compounds from a South-East Asian tropical rainforest, Atmos. Chem. Phys., 10, 
8391-8412, doi:10.5194/acp-10-8391-2010, 2010.

Liu, W., Meng, F. R., Zhang, Y., Liu, Y., and Li, H.: Water input from fog drip in the tropical seasonal rain forest of Xishuangbanna, South-West China, J. Trop. Ecol., 20, 517-524, 2004.

McMillen, R. T.: An eddy correlation technique with extended applicability to non-simple terrain, Bound.-Lay. Meteorol., 43, 231-245, 1988.

Mertes, S., Shröder, F., and Wiedensohler, A.: The particle detection efficiency curve of the TSI-3010 CPC as a function of the temperature difference between saturator and condenser, Aerosol Sci. Tech., 23, 257-261, 1995.

Muller, J. B. A., Coyle, M., Helfter, C., Dorsey, J. R., Gallagher, M. W., Nemitz, E., and Fowler, D.: Ozone fluxes over South-East Asian tropical rainforest and oil palm plantation, Atmos. Chem. Phys. Discuss., in preparation, 2010.

Newbery, D. M., Kennedy, D. N., Petol, G. H., Madani, L., and Ridsdale, C. E.: Primary forest dynamics in lowland dipterocarp forest at Danium Valley, Sabah, Malaysia, and the role of the understorey, Philos. T. Roy. Soc. London B, 354, 1763-1782, 1999.

Paulson, C. A.: The mathematical representation of wind speed and temperature profiles in the unstable atmospheric surface layer, J. Appl. Meteorol., 9, 857-861, 1970.

Pearson, G., Davies, F., and Collier, C.: An analysis of the performance of the UFAM pulsed doppler lidar for observing the boundary layer, J. Atmos. Ocean. Tech., 26, 240-250, 2009.

Pearson, G., Davies, F., and Collier, C.: Remote sensing of the tropical rain forest boundary layer using pulsed Doppler lidar, Atmos. Chem. Phys., 10, 5891-5901, doi:10.5194/acp-10-58912010, 2010.

Phillips, G. J., Di Marco, C. F., Farmer, D., Kimmel, J., Sueper, D., Jimenez, J. L., and Nemitz, E.: Fluxes of sub-micron aerosol chemical components above South East Asian rainforest, Atmos. Chem. Phys. Discuss., in preparation, 2010.

Pinker, R. T. and Holland, J. Z.: Turbulence structure of a tropical forest, Bound.-Lay. Meteorol., 43, 43-63, 1988.

Prenni, A. J., Petters, M. D., Kreidenweis, S. M., Heald, C. L., Martin, S. T., Artaxo, P., Garland, R. M., Wollny, A. G., and Pöschl, U.: Relative roles of biogenic emissions and Saharan dust as ice nuclei in the Amazon basin, Nature Geosci., 2, 402-405, 2009.
Pryor, S. C., Gallagher, M. W., Sievering, H., Larsen, S. E., Barthelmie, R. J., Birsan, F., Nemitz, E., Rinne, J., Kulmala, M., Grönholm, T., Taipale, R., and Vesala, T.: A review of measurement and modelling results of particle atmosphere-surface exchange, Tellus, 60B, 42-75, 2008.

Quant, F. R., Caldow, R., Sem, G. J., and Addison, T. J.: Performance of Condensation Particle Counters with Three Continuous-Flow Designs, J. Aerosol Sci., 23, S405-S408, 1992.

Rissler, J., Vestin, A., Swietlicki, E., Fisch, G., Zhou, J., Artaxo, P., and Andreae, M. O.: Size distribution and hygroscopic properties of aerosol particles from dry-season biomass burning in Amazonia, Atmos. Chem. Phys., 6, 471-491, doi:10.5194/acp6-471-2006, 2006.

Rummel, U., Ammann, C., and Meixner, F. X.: Characterizing turbulent trace gas exchange above a dense tropical rain forest using wavelet and surface renewal analysis, 15th AMS Symposium on Boundary Layers and Turbulence, Boston, Mass., 602-605, 2002.

Ryder, J., Langford, B., Oram, D., Coyle, M., Phillips, G. J., Helfter, C., Misztal, P., Cape, J. N., and Nemitz, E.: Sources and sinks of biogenic volatile organic compounds inside a South-East Asian rainforest canopy, Atmos. Chem. Phys. Discuss., in preparation, 2010.

Vickers, D. and Mahrt, L.: Quality control and flux sampling problems for tower and aircraft data, J. Atmos. Ocean. Tech., 14, 512$526,1997$.

Whitehead, J. D., McFiggans, G., Gallagher, M. W., and Flynn, M. J.: Simultaneous coastal measurements of ozone deposition fluxes and iodine-mediated particle emission fluxes with subsequent CCN formation, Atmos. Chem. Phys., 10, 255-266, doi:10.5194/acp-10-255-2010, 2010.

Williams, P., Gallagher, M., Choularton, T., Coe, H., Bower, K., and McFiggans, G.: Aerosol development and interaction in an urban plume, Aerosol Sci. Tech., 32, 120-126, 2000.

Zhou, J., Swietlicki, E., Hansson, H.-C., and Artaxo, P.: Submicrometer aerosol particle size distribution and hygroscopic growth measured in the Amazon rain forest during the wet season, J. Geophys. Res., 107, 8055, doi:8010.1029/2000JD000203, 2002. 